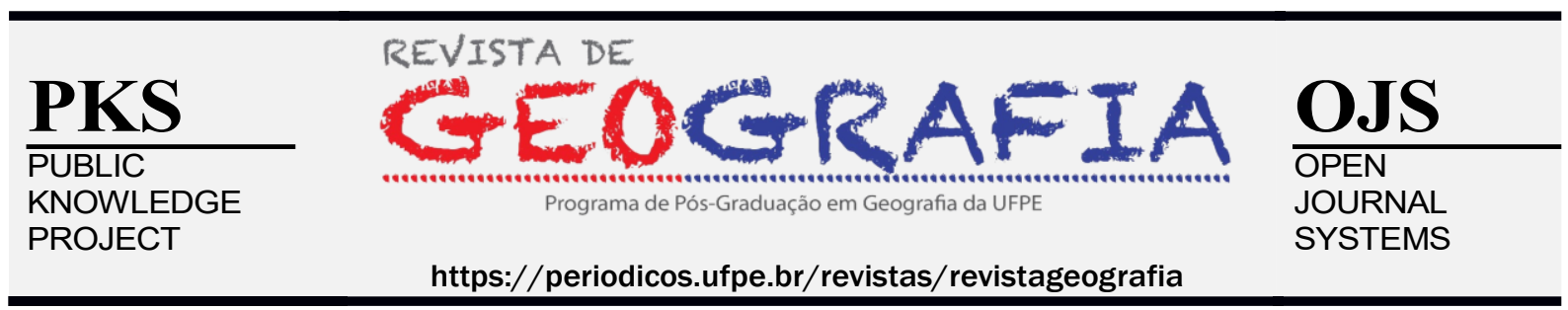

\title{
TOPOGRAFIAS DOS CAMINHOS POSSÍVEIS PARA O CORPO NA GEOGRAFIA
}

\author{
Ewerton Maurício dos Santos ${ }^{1}$ \\ 1 Universidade Federal de Pernambuco. E-mail: ewertu@outlook.com. ORCID: http://orcid.org/0000-0002-
} 1112-1946

Artigo recebido em 21/07/2021 e aceito em 04/10/2021

\begin{abstract}
RESUMO
Este trabalho visa fazer um levantamento de produções acadêmicas, artísticas, que abordam a questão do corpo para tencionar o campo do saber geográfico, e expandir sua compreensão, e assim provocá-lo epistemologicamente a produzir outros fazeres científicos. Guiado através de uma pergunta simples, porém repleta de nuances: "O que é o corpo?", farei esforços para sistematizar as abordagens sobre o corpo na Geografia e outras ciências, a fim de fortalecer o vínculo que tem se estabelecido ao longo dos anos entre a ciência geográfica e o corpo.
\end{abstract}

Palavras-chave: Corpo; Espaço; Geografia; Epistemologia; Território.

\section{TOPOGRAPHY OF POSSIBLE PATHS TO THE “BODY” IN GEOGRAPHY}

\begin{abstract}
This work aims to make a survey of academic and artistic productions, which address the issue of the body to intend the field of geographic knowledge, expanding its understanding and thus provoking it epistemologically to produce other scientific actions. Guided through a simple question, but full of its complexities: "What is the body?", I will make efforts to systematize the approaches on the body in Geography and other sciences, in order to strengthen the bond that has been established over the years between the science of space and the body/corporeity.
\end{abstract}

Keywords: Body; Space; Geography; Epistemology; Território 


\section{INTRODUÇÃO}

A Geografia como tantas outras ciências, e arrisco-me a dizer, uma epistemologia geral do mundo ocidental, tem diversas dificuldades e desfalques nos desdobramentos de suas práxis. Isso por que, as estruturas sociais que fundamentam o horizonte de pensamento e ação geográficas são, em parte, epistemologicamente guiados por colonialidade (do poder, do saber, do ser, da natureza, do gênero) como estruturam diversos autores tais qual Castro-Gòmez (2005), Quijano (2005); Maria Lugones (2008); Grada Kilomba (2020),flexionando uma racionalidade das esferas da vida coletiva que tendem a ser totalitárias e homogeneizantes em detrimento ao conhecimento, e assim ao poder de alguns grupos, ou melhor dizer, corpos e corporalidades, sob outros. Isso implica dizer que as racionalidades operantes na produção da vida ocidental seguem tendências de dominação da racionalidade, subjetividade e outras esferas que sigam padrões eurocêntricos, 'heteronormativos', masculinizantes, patriarcais, capitalistas, neoliberais.

Assim, criar um sentido não hegemônico de vida, requer tratarmos a realidade a partir de outras concepções, outras narrativas, outros sujeitos, outros métodos e conceitos. $\mathrm{Na}$ geografia o percurso da abordagem sobre o corpo e a corporalidade traz um exemplo do que quero nos atentar e assim evoco a necessidade de cada vez mais geógrafos e licenciados interpelarem suas pesquisas, seus debates, suas aulas a partir desse conhecimento, como forma também, de reelaborar e ampliar as abrangências da Geografia e produzir, de muitas formas, renovações. Portanto revisão de literatura sobre o tema em questão, nas diversas ciências foi empreendida neste trabalho, que visa desbravar 'novos oceanos' do conhecimento (GONÇALVES, 2019a; 2019b)

\section{MÉTODO}

A navegação por novos traçados geográficos inspira o método dessa pesquisa, o qual se instrumentaliza uma revisão da literatura de qual me familiarizei ao longo do percurso. Dentre filósofas (os), antropólogas (os) e geógrafas (os), me deparei lendo e aprendendo uma diversidade de artigos e livros, os quais formam uma rede imbricada que levam uns aos outros. Dentro dessa navegação, algumas práticas (yoga, meditação) e cursos (teoria queer), emergiram 
das águas que banham nossa contemporaneidade em busca de 'cosmoperceber' a vida através de pensar e agir corporalmente, ou seja, de aprender e existir, num movimento uno, as nuances que é estar vivo em plena pandemia de Covid-19, num país conservador, neoliberal e com muitos resquícios políticos fascistas. Essa revisão literária assim despertada pela busca cosmopercepitiva de compreender essa realidade em que meu corpo, mente, alma e coração estão intimamente imbricados, e que por isso despertam as pistas e caminhos dos quais decido guiar as leituras. Assim empreendo um método etnográfico, onde "ele é antes um modo de acercamento e apreensão do que um conjunto de procedimentos" (MAGNANI, 2002. p. 17). Desta forma, deixo todas as minhas percepções (corporificadas) me levarem pelos seus caminhos perceptivos, afetivos, sensitivos na busca da projeção de seus dilemas nas teorias. Para essa empreitada é também necessário arriscar, linguisticamente, outras formas de conceber o conhecimento, como Barad (2017), coloca o termo 'ontoepistemologia', nos elucidando de que as formas de conceber o conhecimento e ser, não estão desatreladas, mas comungam mutualmente imbricadas. Ou da escolha metodológica de nos referir "cosmopercepções", ao invés de "cosmovisões", por compreendermos que há uma certa produção na modernidade que privilegia a visão em detrimento aos outros sentidos (LE BRETON, 2012), já que o sentir é a ideia que nos guia metodologicamente.

\section{MAS AFINAL, O QUE É CORPO?}

Questionar-se sobre "o que é o corpo" tenciona diferentes, mas não divergentes, campos do saber, nos dando uma rica abordagem e diversas perspectivas de como elaborar o conhecimento a partir desta enunciação. Da Filosofia à anatomia, passando por elaborações antropológicas, o corpo é um lugar de conhecimento importante na apreensão de diversos fenômenos, mecanismos e filosofias em variados sistemas de organização de mundo.

Das abordagens mais materialistas observando o corpo nas suas circunscrições orgânicas, motoras, neuropsíquicas, químicas, indo até as abordagens de caráter subjetivo, existencial é possível fazer diversos intercruzamentos cognitivos, culturais, sociais e econômicos com a ciência geográfica com o corpo, assim como já era apontado por Lefebvre (1991):

Antes de produzir efeitos na esfera material (ferramentas e objetos), antes de se produzir, por alimentar-se daquela esfera material e antes de se reproduzir, 
gerando outros organismos, cada corpo vivo é espaço e tem seu espaço: ele se produz no espaço e também produz esse espaço (LEFEBVRE, 1991, p. 405, tradução nossa).

Lefebvre, assim, levanta algumas primeiras questões que são interessantes de se pensar: i) Persiste aqui uma dicotomia entre "corpo x espaço", que guia epistemologicamente nossa compreensão geográfica sobre o corpo? Quando o autor coloca uma 'esfera material' como algo 'externo' ao corpo, ele reverbera essa dicotomia? ii) Na passagem onde Lefebvre diz: 'cada corpo vivo é espaço', ele quer diluir essa dicotomia, ou apontar um tipo de espacialidade diferente daquela a qual conhecemos na ciência geográfica? iii) Se há uma tentativa de dizer que o corpo é espaço, então precisamos repensar nossos arcabouços conceituais?

Bem, essas perguntas estão longe de esgotar, sanar ou apontar um único caminho para o debate. Particularmente, desses desdobramentos me inflige uma segunda questão, tão primordial quanto entender "o que é o corpo": há como conceber o corpo como espaço compreendendo algum fluxo dialético entre uma instância e outra (interioridade e exterioridade), sem que caiamos numa lógica dicotômica?

Navegando pelos significados agrupados no dicionário online Michaelis ${ }^{1}$, nos debruçamos com mais de trinta definições para a palavra "corpo", o que alerta para uma polissemia da qual preferimos fazer uma cisão no campo da anatomia. Aliás, é deste corpo 'humano', por hora, do qual nos referimos, e assim algumas definições apareceram aqui em detrimento de outras.

As definições de caráter mais materialista, onde à anatomia é mais proeminente na construção do significado, colocam o corpo como: 1) conjunto de elementos físicos que constitui o organismo do homem ou do animal, formado por cabeça, tronco e membros. 2) A estrutura física de uma pessoa; 3) Formação anatômica, embriológica ou histológica. Vale lembrar que essas definições podem circunscrever tanto um corpo dotado de 'vida', quanto o de um 'cadáver', tanto quanto podemos estar, no caso da definição um e três, abarcar o corpo 'humano' do corpo 'animal'. Na terceira definição, ainda é abarcado as características da histologia, onde uma célula, órgãos podem ser considerados como corpo.

Tirando, primordialmente por essas definições, podemos de certa forma, perceber que o corpo, como uma circunscrição física, motora, material, biológica de um ser, é algo físico,

\footnotetext{
${ }^{1}$ Disponível em: Corpo | Michaelis On-line (uol.com.br). Último acesso em: 10/07/2021 17:28
} 
dotado de potências variadas por conta de sua estrutura material. Segundo, o que acho importante frisar: o que foi até aqui elaborado é uma perspectiva!

Ou seja, ao escolher denotar o corpo através da anatomia, estamos recortando uma realidade, uma forma 'ontoepistemológica' de conceber as estruturas cosmoperceptivas da vida, para uma determinada elaboração do sistema-mundo. Assoamos esse alarme pois há uma gama de perspectivas a serem consideradas, como a dos povos originários que não se utilizam do sistema de signos-significados que nossa 'modernidade' impõe. Tratamos como um exemplo os Juruna, um pequeno povo tupi do rio Xingu, onde De Lima (2002) faz um trabalho antropológico na busca da pergunta fundante deste artigo: "O que é um corpo?"

Lima, percorre os significados através da construção da linguística dos Juruna, e percebe que os significados para corpo não são "hipótese alguma, povoado por corpos separados uns dos outros e do mundo, separados justamente por esse princípio de isolamento, fixação, autonomia e individuação que nos é peculiar” (p. 3).

É na conjugação de alma e pele, que o povo Juruna compreende a inseparabilidade de um plano material e metafísico, em que o corpo e seu sistema de elaborações é cosmopercebido através de uma perspectiva, onde o que distingue um 'humano' de um 'animal' é só o invólucro da pele que representa a alma. Para os Juruna é possível se tornar onça, macaco, cobra ao 'trocar de pele', e esses animais são, também, uma espécie de 'capa', "lançada pelo criador a um certo conjunto da humanidade" (LIMA, 2002, p. 6).

Este jogo de perspectivas, cria para os Juruna uma complexa relação existencial, filosófica, em que não é possível, em antagonismo as definições da anatomia, conceber o que é um corpo sem compreender as relações ontológicas profundas entre a espécie humana e tudo o que compõe o mundo: animais, fauna, flora etc. Nesse jogo de perspectiva Lima (2002) traz um exemplo emblemático de como podemos compreender essa elaboração:

(...) para os urubus, o fedor de carniça é uma coluna de fumaça, a própria carniça é um moqueado, os vermes são pó de pimenta. Em resumo, pessoas, carniça, vermes, urubus, mas também rio, pedra e assim por diante, existem antes de tudo como perspectivas humanas e, enquanto tais, são corpos fundamentalmente distintos em outras perspectivas (p. 5). 
$\mathrm{Na}$ arte, Mc Kurumin (SP), nos oferece uma outra perspectiva de corpo da qual podemos debruçar em seu esplendor. No videoclipe de Xondaro Ka'aguy Reguá, disponível no Youtube ${ }^{2}$, Kurumi, aldeia de Krukutu, na região de Parelheiros, na zona sul de São Paulo, canta autenticamente sobre os processos de colonização e colonialidade, em que as escrituras sagradas Guaranis estão em evidência em seus versos. Na construção visual (Figura 1), Kurumi nos entrega o que quero aqui representar.

Figura 1: Kurumi MC, no videoclipe Xondaro Ka'aguy Reguá, confunde seu próprio corpo com a mata.

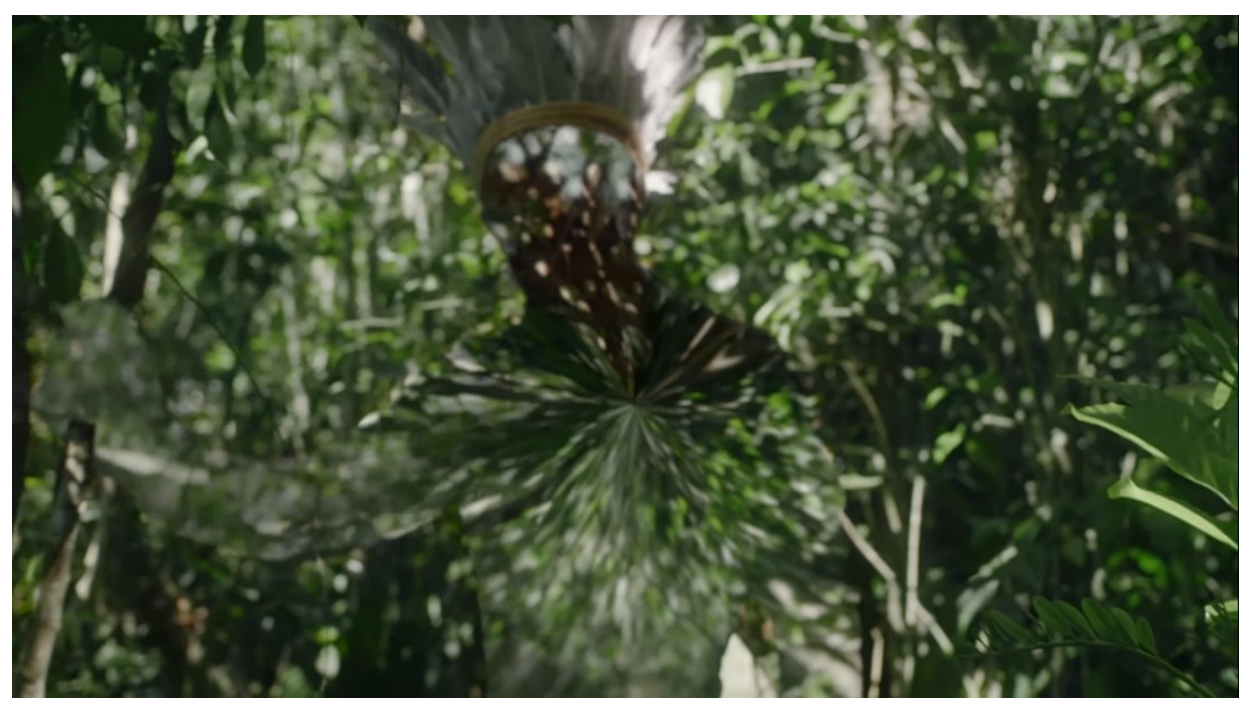

Fonte: Reprodução Youtube.

Em diversas passagens do seu videoclipe, o rapper nos mostra a silhueta do seu corpo em transparência com a mata e outros elementos da natureza: fogo, raios, chuva, rios. A alusão de representar-se como parte da natureza, como relata nos seus primeiros versos: "Existe uma lenda Guarani muito antiga, contada pelos nossos ancestrais. Ela diz que das águas nascerá um guerreiro que levará o seu povo a uma nova existência", remontada em meio a versos em que ele denuncia a perseguição e a guerra contra povos originários, e o desprezo por suas ciências e tecnologias, nos faz perceber que essa individualidade, esse corpo, é conjugação intrínseca de espaço-técnica-ciência, e que destruição territorial, pelas múltiplas vias encontradas pelo capitalismo predatório ao longo de cinco séculos de dominação, significa igualmente a destruição de corpos-territórios, de sujeitos, saberes, ciências, filosofias, formas

\footnotetext{
2 Disponível em: (2) Kunumi MC - Xondaro Ka'aguy Reguá (Official Video) - YouTube. Último Acesso em: 10/07/2021 - 18:01.
} 
de sistema-mundo que jamais poderão ser recuperadas. Esse espetáculo visual fornecido pelo Mc, nos faz questionar quais são os limiares entre o corpo e o espaço. Em quais escalas, intensidades e definições somos o espaço que nos circunda, e ele é o que somos?

Continuando nas provocações artísticas dois artistas nos mostram perspectivas interessantes de uma relação corpo-espaço, que nos empenharemos a cativar. O primeiro deles, Jaloo (PA), dedica uma faixa ${ }^{3}$ coreografada para cantar sobre a chuva (Figura 2). Em seus trechos, o paraense narra o ciclo da chuva ao ritmo do Carimbó, o que desperta a atenção das relações ritualísticas entre povos originários, nativos, suas representações sagradas e como os corpos estão intimamente ligados na produção dos signos e significados.

Figura 2: Jaloo performa 'Chuva', canção de seu primeiro álbum de estúdio, enquanto encarna uma entidade.

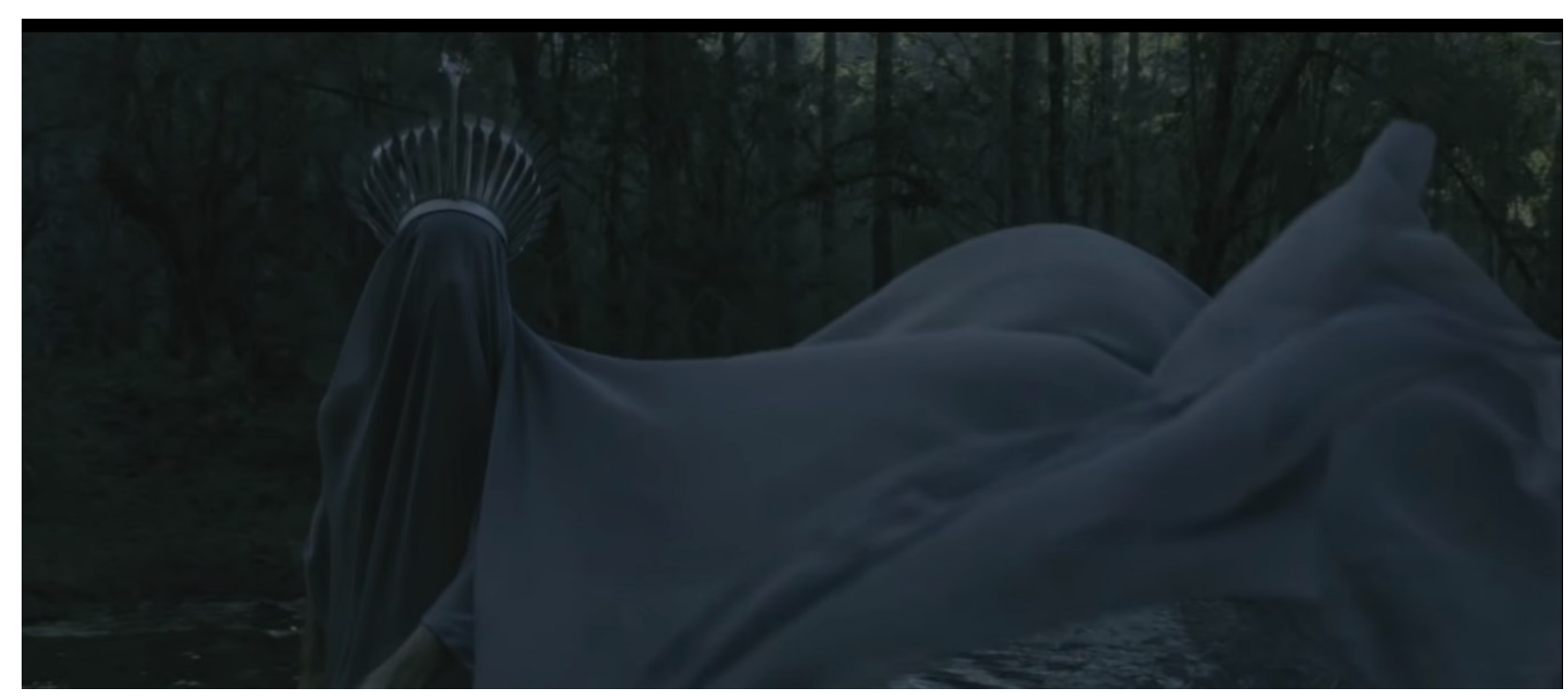

Fonte/Reprodução: Youtube.

No segundo caso, Kia Labeija, poetisa visual (Figura 3), coreografa a canção "Dove”, ${ }^{4}$ do cantor Pillar Point (Seattle), pelas ruas de Bogotá, em busca de seu “amor". Na provocação dessa experiência visual, Kia nos desperta uma intrigante questão de como as cidades não são 'funcionais' para algumas expressões, intervenções de corpos, ao mesmo tempo que sua concretude parece inspirar outras possibilidades de ser e estar em movimento na cidade.

\footnotetext{
${ }^{3}$ Disponível em: (2) Jaloo - Chuva (Clipe Oficial) - YouTube. Último acesso em: 12/07/2021-15:21

${ }^{4}$ Disponível em: (2) Pillar Point - Dove [OFFICIAL MUSIC VIDEO] - YouTube. Último acesso em: 12/07/2021 as 16:01.
} 
Figura 3: Kia Labeija se move de forma pouco 'usual' pelas ruas de Bogotá, na Colômbia. Apesar da estranheza, há algo de suspenso na performance que nos faz questionar profundamente as relações corpo-espaço.

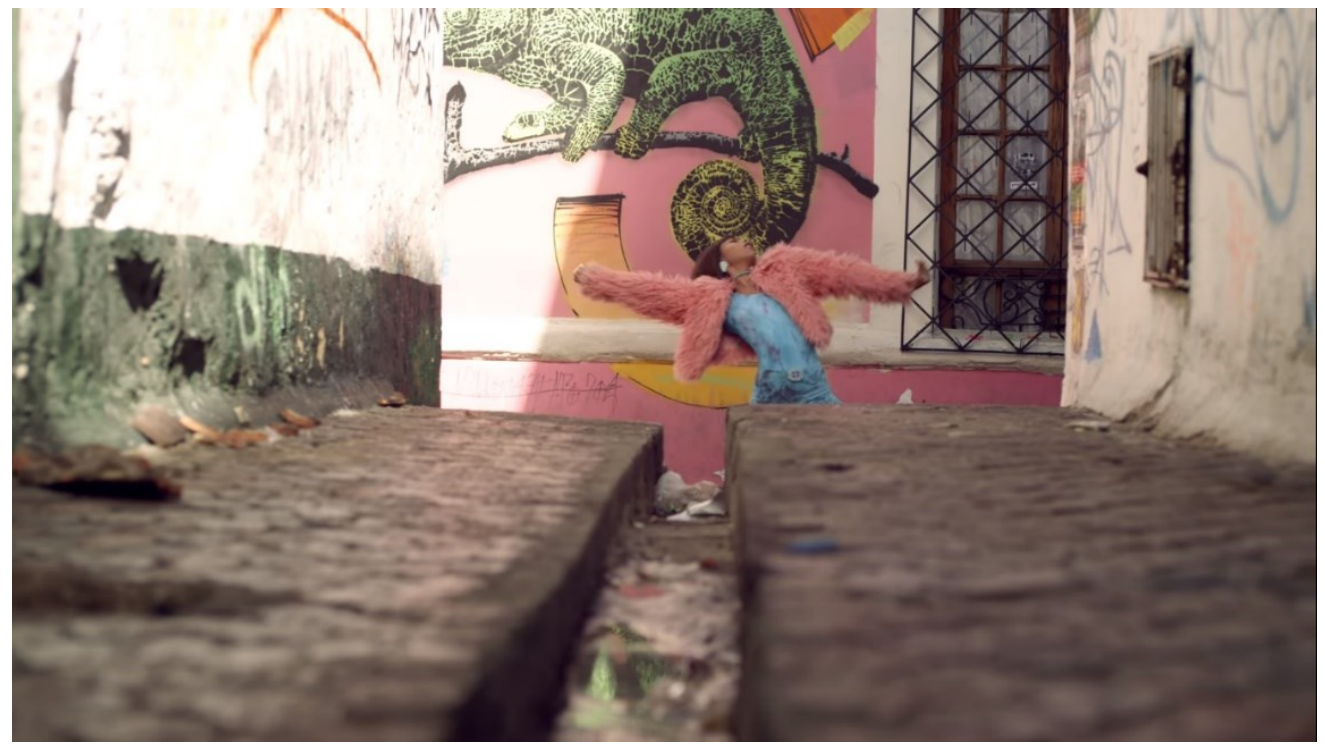

Fonte/Reprodução: Youtube.

O 'jogo visual' de Kia aguça os sentidos ao subjetivar essas questões e nos despertar para um constrangimento "performativo" (BUTLLER, 2012) de nossas expressões, nossa gestualidade que parecem ser regras 'invisíveis', normas subjetivas que pairam no ar nas cidades e seus espaços públicos. Assim é possível pensar em uma espacialidade, territorialidade construída pelos corpos e nos corpos que possam criar tipologias de cidades, espaços, levando em consideração as relações entre corpo-cidade? Quais ebulições em perspectivas e conhecimentos se emergem de um pressuposto sistema "corpo-cidade" para a geografia? A arte aponta novos topos e horizontes a serem levados em consideração nessa complexa relação corpo-espaço que podem ser de deleite geográfico. Uma vez que exprime à amplitude neste debate que comumente não conjuga com as áreas artísticas do conhecimento.

Essa constituição de perspectivas revela as complexas relações que compõe os limiares da compreensão do que é um corpo, de acordo com pontos cosmoperceptivos diferentes, mas que partem de um ponto análogo. Debruçados num amplo debate ao longo dos anos, pesquisadoras (es) como Henri Lefebvre (1991), Judith Butler (1999), Elias Lopes de Lima (2007), Yi-Fu Tuan (2012), Joseli Maria (2016), José Ornat (2019), Alides Baptista Chimin (2019), Rogério Haesbaert (2020), tem o corpo/corporalidade, como uma das centralidades nas suas discussões, ora fazendo contribuições filosóficas na geografia, ora inserindo as modalidades corpóreas, órgãos e sentidos no intenso jogo de produção social do espaço. Cada 
um desses trabalhos aborda o corpo de diferentes maneiras na produção do conhecimento geográfico.

Nos caminhos do pensamento decolonial, como exemplo, o corpo é arquitetado como corpo-território. Essa categoria é para Miranda (2020, p. 25-26) um "texto vivo, um texto-corpo que narra as histórias e as experiências que o atravessa", fruto de "encruzilhadas experienciais" as quais as partes sensoriais do corpo (visão-olhos; paladar-boca-língua; olfato-nariz; tatomãos-pés-pele etc.), fornecem um fluxo dialético de percepções, elaborações e ações no mundo interno e externo. Essa conjugação permite ao corpo, segundo o autor, a autenticidade de viver/existir através de seus próprios códigos, deixando de sucumbir "a viver pela linguagem e experiência do outro" (p. 27), abrindo assim, possibilidades para que outras “ontoepistemologias” (MORAES e PARRA, 2020) além das coloniais, fundem as raízes, criem o solo, desenvolvam a 'fauna-flora', o clima, a topografia da existência individual e coletiva.

O território ganha assim, uma conjugação que vai para além da sua contextualização clássica, que leva em consideração a escala, esta "socialmente construída" (SILVA e ORNAT, 2016), e suas ligações à lógica estatal, flexionando em si conceitos como a "defesa da própria vida, da existência ou de uma ontologia terrena/territorial" (HAESBAERT, 2020, p.76). Assim, o território, ou o espaço, como queira, está imbricado ontologicamente a existência de corpos e corporalidades, que ganha aqui um sentido para além de sua circunscrição física, abarcando práxis imateriais, 'ontoepistémicas', filosóficas e artísticas em seu escopo.

Ainda tencionando o campo filosófico, o corpo ganha outras dimensões de leitura que podem/devem interessar à compreensão da ciência geográfica. Na filosofia, a abordagem de Merleau-Ponty (1999), já foi explorada por Elias Lopes de Lima (2007), quando o autor, busca na filosofia 'Pontyana' as bases para o rompimento da ideia de um espaço único e absoluto, e trata que o "ser corpo" é "estar atado a um certo mundo, e nosso corpo não está primeiramente no espaço: ele é no espaço" (MERLEAU-PONTY, 1999, p. 205).

Para Lima (2007), ao afirmar que o corpo é no espaço, o filósofo abre uma porta para compreender a existência íntima ou ontologicamente espacial e temporal, "expressos respectivamente em seus correlatos ontológicos ser e estar” (p. 66). Assim, se a existência humana é corporificada, temos uma definição para corpo que conjuga existencialmente a história e a geografia, ou seja, os corpos/corporalidades são de certo modo forjados e forjam situações históricas e geográficas específicas. Merleau-Ponty ainda nos engrandece com a passagem em que trata da espacialidade como "o desdobramento de seu ser de corpo, a maneira 
pela qual ele se realiza como corpo" (MERLEAU-PONTY, 1999, p. 206), o que leva a Lima (2007) a nos atentar que:

O ordenamento de nossas percepções supõe uma relação de reciprocidade em que corpo e espaço se implicam mutuamente. Para um indivíduo não haveria espaço se ele próprio não fosse um corpo no mundo, ou seja, ele é no espaço. (...) Nesse sentido, toda experiência corporal é por definição e princípio uma experiência espacial (LIMA, 2007, p. 67).

Ao inferir que 'o corpo é no espaço' e que 'ser corpo é estar atado a um certo mundo', Merleau-Ponty nos deixa imaginar que só é possível ser um corpo no mundo, e só é possível um mundo a partir do corpo. Ou seja, esse mundo é espacial, assim como o corpo. Em outras palavras, não existe espaço se não existe corpo e vise verso, o corpo só se conjuga no espaço e o espaço só se conjuga no corpo. O corpo, assim, conjuga território. O território, o lugar, as paisagens, a espacialidade são desencadeamentos do 'uno " corporalidades-espacialidades". O corpo está intimamente conectado com o território, lugar, espaço e paisagem: em um fluxo ininterrupto, em redes, produzindo e sendo produzido pela espacialidade, seus sistemas de objetos e de ações (SANTOS, 1996).

Ainda nos desdobramentos filosóficos, Judith Butler (2012), conhecida por ter uma trajetória acadêmica de contestação das formas generificadas da vida, aborda ao decorrer de sua obra, as demarcações do corpo para a compreensão de uma sociedade que, de forma social e cultural, cria diversos modos corporificados de vida. Baseada nas circunscrições de ordem biológica e social, como o sexo, gênero e raça, Butler $(1999,2011)$ esquematiza como a sociedade esboça para os corpos modos de vida que tem repertórios gestuais, comportamentais, psíquicos, territoriais etc., preenchidos de um repertório simbólico, subjetivo e material que dão continuidade a projetos de poder instaurados socialmente, projetos estes de ideais masculinos, patriarcais, hétero conformes, cis.

Essa subjugação das modalidades corporais (gênero, sexo, raça, capacidades físicas, idades) determinam estigmas de indivíduos que marginalizados, violentados ou 'extintos' fazem parte de tristes estatísticas sociais ${ }^{5}$. Assim, Butler nos elucida que o corpo não deve ser lido de forma neutra, imparcial e universal, pois são socialmente atribuídos lugares e territórios a esses corpos que podem definir quem são e quem não são dignos de humanidade.

\footnotetext{
${ }^{5}$ O Brasil, por exemplo, é líder mundial em mortes violentas por LGBTFobia. Relatório disponível em: https://static.poder360.com.br/2021/05/Observatorio-de-Mortes-Violentas-de-LGBTI-13mai2021.pdf
} 
É nessa pegada elucidativa que Grada Kilomba (2020) nos traz valiosas contribuições para compreender o corpo negro, racializado num projeto de modernidade, capitalista e colonial, como divisor dos direitos à humanidade, ou seja, a quais corpos são concebidos socialmente como sendo "humanos". Nesse sentido, o retrato da escrava Anastácia (Figura 4), nos permite trazer à tona questões que enriquecem nossas contestações: 1) As diferentes modalidades do corpo, e nesse caso, a racial, definem a produção social do espaço e as relações de produção (SILVA; ORNAT; JUNIOR, 2019), colocando corpos em privilégios sociais em detrimento de outros, assim definindo hierarquias de poder; 2) Os corpos, estes capturados pelo sistema produtivo, ora como mercadorias, ora como ferramentas para o trabalho, é desigualmente distribuído nas divisões territoriais, sexuais e sociais do trabalho ${ }^{6}$, dependendo, sobretudo, de suas modalidades (raça, gênero, sexualidade, capacidade física etc.) e de suas trajetórias econômicas-sociais. 3) O corpo/corporalidade tem sido historicamente um instrumento importante de controle social, e o genocídio do período colonial-escravagista cria uma condição de desumanidade para um contingente de corpos.

Figura 4: Retrato da "Escrava Anastácia", nome a ela atribuído durante o período escravocrata no Brasil. Segundo Grada Kilomba (2020) o uso do colar de ferro e da máscara facial podem estar atrelados a castigos por suas insurgências, vindas de seu ativismo político para com outres escravizados (as/es), junto a resitência aos atos do estupro do "senhor" branco.

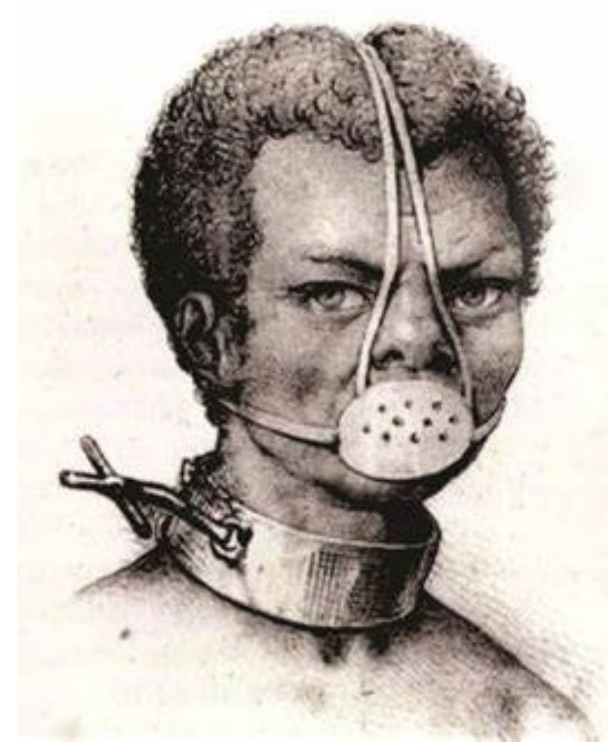

Fonte: Memórias da Plantação, Grada Kilomba (2020).

\footnotetext{
${ }^{6}$ Racismo estrutural segrega negros no mercado de trabalho - CUT - Central Única dos Trabalhadores
} 
Deste ponto da discussão, a colonização-escravidão como movimento histórico então, cria o que Patzdorf (2021) chama genericamente de 'disciplinamento do corpo'. O autor sugere que a destituição geográfica-cultural foi condição necessária para se 'fabricar' novos corpos. A partir de uma 'forja' de subjetividades, o processo colonial-industrial é também uma sujeição cultural, que subjuga 'corpos-territórios-subjetividades' a relações políticas, territoriais, sociológicas etc., produzindo a sociedade/corpos/corporalidades através da coerção e de vários tipos de violências: micro e macros, normalmente protagonizadas por algozes: senhores de engenho, capitães do mato etc. (GRADA, 2020).

Mais tarde, historicamente, a imposição da violência física dá lugar a processos "biopolíticos" capazes de determinar as condições de reprodução territorial, cultural e social do capitalismo através das subjetividades individuais (FOUCAULT, 2004). Patzdorf (2021), acredita que é o processo de colonização que 'desencanta os corpos', ao desconectá-los de seus territórios ancestrais, de articulá-los de suas comunidades, desmembrando material e simbolicamente todos os recursos que os sujeitos teriam ao seu dispor para a vida. Para isso a submissão desses corpos as mais variadas formas de violência, dor, torturas, e todas as mazelas do processo de escravidão, cria as condições necessárias para destruir práticas e cultos, culturas, seus símbolos e significados, arruinando, desta forma, 'corpos-territórios'.

Essa perspectiva nos dá um sinal perceptivo-sensitivo dos envolvimentos do corpo com a cultura. Desorganizar culturas é outrossim de destruir territórios, extinguir a imaterialidade que compõe cada corpo, ou se nos apetece: a sua alma. Na mesma via, quando tratamos do aparato simbólico das relações assimétricas de poder, tem um papel importante no que Foucault, vai inferir como "biopoder", temos mais uma camada de densidade em torno dessa busca por uma definição de corpo:

O momento histórico das disciplinas é o momento em que nasce uma arte do corpo humano, que visa não unicamente o aumento de suas habilidades, nem tampouco aprofundar sua sujeição, mas a formação de uma relação que no mesmo mecanismo o torna tanto mais obediente quanto é mais útil, e inversamente. Forma-se então uma política das coerções que são um trabalho sobre o corpo, uma manipulação calculada de seus elementos, de seus gestos, de seus comportamentos. O corpo humano entra numa maquinaria de poder que o esquadrinha, o desarticula e o recompõe. Uma "anatomia política", que é também igualmente uma "mecânica do poder", está nascendo; ela define como se pode ter domínio sobre o corpo dos outros, não simplesmente para que façam o que se quer, mas para que operem como se quer, com as técnicas, segundo a rapidez e a eficácia que se determina. A disciplina fabrica assim 
corpos submissos e exercitados, corpos "dóceis" (Foucault, 2004, p. 133, grifos nossos).

Para as definições de Foucault (2004, p.3) é importante se atentar que as noções de governança em si, tem um grande apelo ao "guiar os homens, de dirigir as suas condutas, de constranger as suas ações e reações”. Andrade (2019), nos lembra que algum arranjo de governança, como o Neoliberalismo, é também capaz de criar uma subjetividade que se impregnam nas subjetividades dos sujeitos, assim de seus corpos, e os fazem crer que as normas que devem prevalecer na estrutura de seus comportamentos, devem ser àquelas cuja são as do mercado: competição e rentabilidade.

Esses pressupostos desencadeiam a ideologia de um "empreendedorismo de si", onde cada indivíduo compete com os outros, assim tal como empresas competem entre si, criando uma atmosfera de auto responsabilização, que em uma de suas dimensões levam corpos e corporalidades a manterem formas gestuais, comportamentais, psíquicas em detrimento do rearranjo das esferas da vida pelo mercado.

Assim essa sociedade, seus aparatos e imperativos que coordenam as normas de produção e reprodução social, as fazem, em uma de suas esferas, nas formas de percepção dos indivíduos, percepções essas que são sempre corporificadas (MERLEAU-PONTY,1999). Nesse ethos, onde o sujeito se vigia enquanto vigia o outro, se pune enquanto pune o outro, transfigura formas de produção de diversos tipos de sofrimento, o que está intimamente coligado com os altos índices de suicídio ${ }^{7}$, depressão, ansiedades ${ }^{8}$ no Brasil e no mundo (SAFATLE; SILVA JR; DUNKER, 2021).

Todo esse desdobramento nos significa que a conjugação de uma definição para corpo, não pode ser desatrelada, em nenhum momento, de suas capacidades sensoriais, sejam elas puramente dos sentidos, ligado a órgãos específicos do corpo, ou seja de forma coordenada junto à subjetividade, os afetos, a psique humana, que decodifica e 'somatiza' resultados dos movimentos da sociedade. Para Dunker (2017), como exemplo, "a forma de vida neoliberal descobriu que se pode extrair mais produção e mais gozo do próprio sofrimento" (p. 284), criando artefatos nas dimensões imateriais da vida humana, um campo propício para a fabricação de novas dependências, desejos e mercadorias.

\footnotetext{
${ }^{7}$ Dados da Organização Mundial da Saúde. Disponível em: Suicide (who.int). Último acesso em: 20/06/2021

8 Dados da Organização Mundial da Saúde. Disponível em: Brazil (who.int). Último acesso em: 20/06/2021
} 
Daí o corpo se conjuga como uma obra, artesanato, dos movimentos políticos, econômicos e sociais dos quais ele participa, tanto como 'ator', como 'palco'. Nas novas configurações 'técnicas-científicas-informacionais' (SANTOS, 1996) dos tempos atuais, também podemos observar diversos fenômenos aos quais a internalização de métodos, contribui par a par na relação entre corpo e sociedade. Destaquemos o exemplo das tecnologias de reconhecimento facial, demasiadamente usadas nos setores de segurança pública e privada, mas também em aplicativos de redes sociais, tais quais figuram Big techs (Facebook, Google, Microsoft etc.). Já há casos registrados de uma falha nesse tipo de tecnologia, que tem em sua constituição maiores probabilidades de erro em reconhecer suspeitos quando estes são negros 9 .

Ora, não estaríamos nós, diante de mais um instrumento de controle, que forjado em suas constituições de software e hardware por pessoas/corpos/subjetividades, tornam-se mecanismos de reforço das desigualdades, violências e injustiças para determinados tipos de corpos? Reforçando estruturas coloniais, e por isso racistas, e seus territórios e territorialidades?! Para Patzdorf (2021), esse novo conjunto técnico, tem em suas potencialidades a produção de mercadorias em formatos imagéticos, informacionais e de experiências, ou seja, impalpáveis, imateriais, tem potencialidades mais que nunca, de se 'tentacular' para o único lugar possível de compreender, assimilar, produzir e reproduzir essas referências: o corpo, este, relembrando, dotado de subjetividade, de capacidades psíquicas-cognitivas, neuro afetivas, necessárias para a produção e reprodução de mundos de vida. Deste modo, Preciado nos articula com uma valiosa percepção desses regimes:

Testemunhamos progressivamente a miniaturização, internalização e introversão reflexiva (movimento de torção para o interior, para o espaço considerado como íntimo e privado) dos mecanismos de controle e do regime sexopolítico disciplinador. Essas novas tecnologias suaves de microcontrole adotam a forma do corpo que controlam, transformam-se em corpo, até se tornarem inseparáveis e indistinguíveis dele, acabando como soma-tecnosubjetividades. $O$ corpo já não habita os espaços disciplinadores: está habitado por eles. A estrutura orgânica e biomolecular do corpo é o último esconderijo desses sistemas biopoliticos de controle (PRECIADO, 2018, p. 86 , grifos nossos).

Bem, a forma de ser e estar no mundo mediada pelo trabalho, dinheiro, mercado, troca e mercadorias no sistema capitalista é, também, uma forma de pensar e organizar nossas sensibilidades, nossas gestualidades e nossas conexões com o que há no mundo. Em

\footnotetext{
${ }^{9}$ Reportagem do Detroit Free Press. Disponível em: Detroit facial recognition technology has misidentified suspects (freep.com). Último acesso em: 20/06/2021
} 
contrapartida ao mundo capitalista, a razão que guia os povos originários não organiza a sociedade sob esses pretextos. As capacidades de enxergar, ter, agir, sentir, perceber e filosofar o mundo dos povos originários, não diluem o capitalismo, colonialismo ou o neoliberalismo. Assim, a organização de sujeitas (os), subjetividades, práticas, tem uma mudança 'ontoepistemológica', existencial, umas outras práxis.

Não se pode dizer que um trabalhador assalariado, ou um "empreendedor" 'informal' de uma metrópole urbana brasileira, tem as mesmas gestualidades, sensibilidades e sociabilidades de alguém organizado no interior de um povo originário. Essas instâncias compõe as formas que os corpos irão se comportar, e o que eles irão "somatizar" de suas formas de viver, de suas territorialidades, pois os elementos, regras e filosofias que instituem os espaços e espacialidades de suas vidas são elementos chaves para sua corporalidade.

Se vivemos inseridos em um sistema 'hereto-cisconforme', com comportamentos e gestualidades bem definidas em modalidades de gênero, teremos corpos se comportando, percebendo e concebendo o mundo dentro dessa racionalidade, apesar de não ser um imperativo instransponível. O corpo 'individual' é, por isso, uma escala dessas composições, desse arranjo espaço-sócio-político de cada sociedade, e podem influir em processos gestuais, ritualísticos, psicossomáticos, afetivos, perceptivos-sensoriais (TUAN, 2012; PATZDORF, 2021).

Há também outras perspectivas elaboradas no âmbito da geografia, da saúde e da arte que podem nos fornecer outras pistas, cosmopercepções e enunciados para desenharmos as topografias possíveis para o corpo em nossas definições.

A primeira delas, um mapa conceitual (Figura 5) elaborado pelo Instituto de Salud Socioambiental juntamente com a Fundación Rosa Luxemburgo, disponibilizado pelo site de investigação colaborativa Iconoclastas ${ }^{\mathbf{1 0}}$, nos revela a profunda ligação entre processos produtivos e atividades econômicas como o agronegócio, o extrativismo mineral, infraestruturas energéticas na produção de nossos corpos.

O mapa/esquema corporal intitulado "10 problemáticas socioambientales en la Argentina y Sudamérica, y sus graves consecuencias en la salud - Cuerpo - Território", se propõe a revelar "los impactos en la salud de las comunidades en distintas regiones sudamericanas como consecuencia de la instalación de proyectos de la industria extractiva" (Iconoclastas, 2021). Apesar do trabalho não ter a finalidade de fazer uma definição

${ }^{10}$ Disponível em: https://iconoclasistas.net/. Último acesso em: 30 de Junho de 2021. 
estritamente acadêmica, de interesse da Geografia para o que denomina de "Cuerpo-Território", ele nos permite vislumbrar que há uma rede de fluxos, conexões, entre as formas de produção de mais valor no território da América do Sul e os corpos das pessoas, animais, plantas e o da terra. Essa relação profunda que nos soa muito maior do que apenas causa-consequência, mas pode ser compreendida nos termos de Merleau-Ponty, aqui já mencionados: "o corpo é no espaço”, nos permite, mais uma vez, articular essas aparentes duas instâncias em uma única.

Figura 5: Mapa conceitual busca traçar um paralelo dos problemas socioambientais na América do Sul e suas correspondências com o corpo humano, forjando uma reivindicação política (corpo-território)

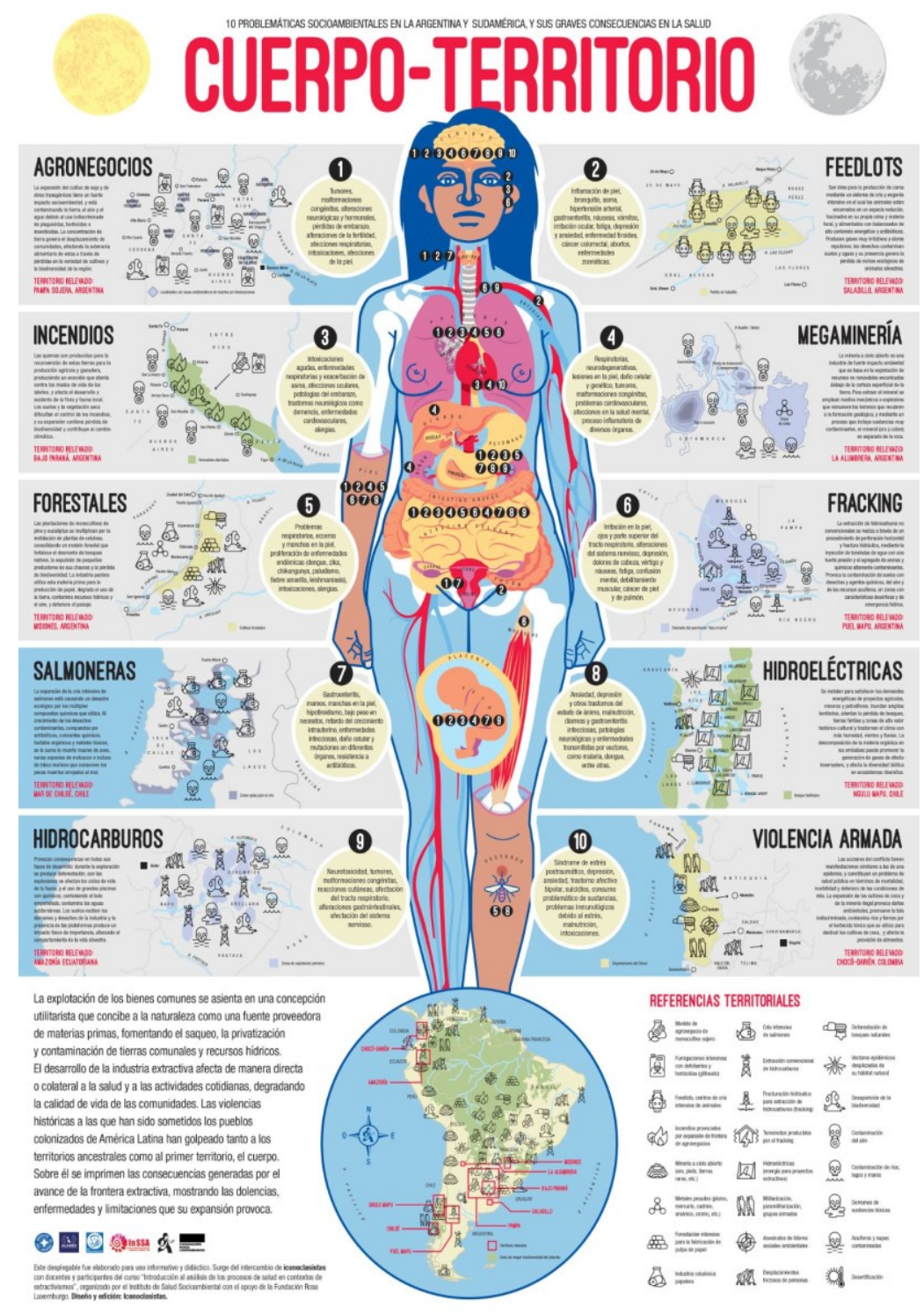

Fonte: Site Iconoclastas 
A segunda abordagem, vem de um ensaio fotográfico, artístico (Figura 6), que compreende o corpo como "un lugar y una superficie de vida, lleno de emociones diversas. Un territorio donde se dibujan puentes, caminos y fronteras que atraviesan cicatrices, lunares, memorias y las marcas del tiempo.” (ACOSTA, 2018, p. 163).

O prisma aqui apresentado, faz a comparação de fotografias de partes do corpo de mulheres com mapas, cartografias que se assemelham em suas curvas, planos, retas, pontos, na medida em que se insere a problemática das cidades como construções de uma estrutura repressiva, autoritária de dominação e subalternização de alguns corpos e corporalidades, como é no caso das mulheres, sejam elas cis ou trans, não-binárias, racializadas, com alguma deficiência psíquica-motora, jovem ou senil, enfim, de todas as modalidades que o corpo pode expressar. Essas formas de dominio, segundo a autora "atraviesan la piel y las decisiones, estructuras de dominación que despiertan culpas y estigmas, que se marcan como huellas en el territorio" (p. 163), assim para ela, o corpo é "un espacio de resistencia y un eje de rebeldías." (Idem).

Figura 6: Imagens, mapas e poesias compõe o ensaio visual de Sofia Costa, que busca um paralelo entre os corpos e a cidade

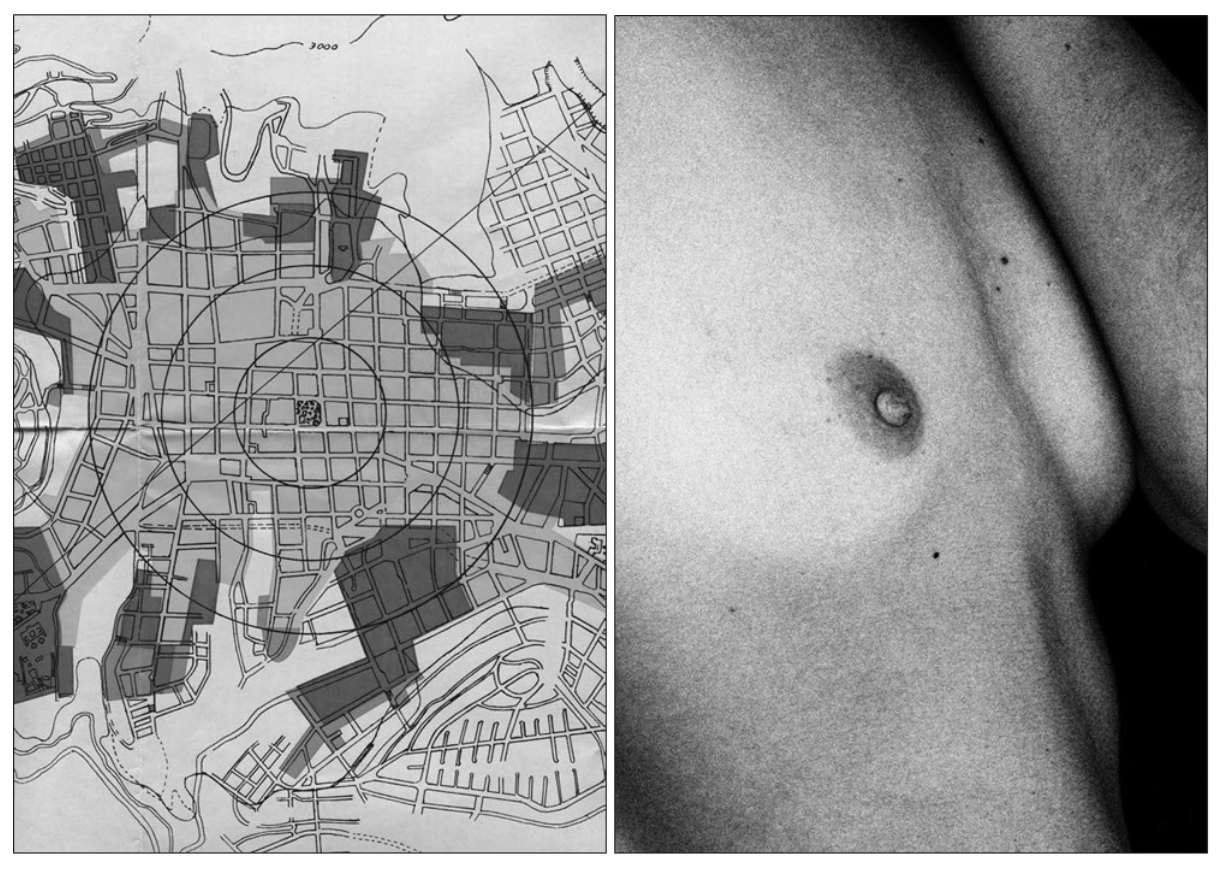

Fonte: ACOSTA (2018) 
Esse paralelo traçado por Acosta (2018), uma tentativa simbólica-visual, nos permite ter outras perspectivas de uma geografia corporizada, que forja seus limites para compreender as "metanarrativas" que percebem o corpo envolvido em todas as tramas e composições sociais, culturais, políticas, espaço-territoriais, nas paisagens, nos lugares (WOODYER, 2008). As tramas que envolvem o corpo na produção do espaço já foram elaboradas por Lefebvre (1991)

O corpo representado pelas imagens da publicidade (as pernas pelas meias, os seios pelos sutiãs, o rosto pela maquiagem, etc.), serve para fragmentar o desejo e condená-lo à frustração ansiosa e à insatisfação das necessidades locais. No espaço abstrato onde quer que se sinta sua influência, a morte do corpo se cumpre de duas maneiras: uma simbólica e outra concreta: concreta como efeito da violência, simbólica mediante a fragmentação do corpo vivo. Isto é particularmente verdadeiro no caso do corpo feminino, transformando em valor de troca, signo de mercadoria e ele mesmo em mercadoria. (LEFEBVRE, 1991, p. 309-310, tradução de SILVA; ORNAT; JUNIOR, [2019])

Esses corpos estão, segundo Sodré:

(...) em meio às pressões individualistas da indústria e do consumo, eventualmente mitigadas pela religiosidade de base sacerdotal e constantemente invocadas pelos dispositivos do espetáculo midiático, sempre tendentes a oferecer-se como compensação diária para a angústia da existência ou para as síndromes depressivas. (SODRÉ, 2014, p.12)

Para esse autor, que faz sua interlocução nos lembrando que existe uma prática epistemologicamente guiada pela corporalidade, como a dança e as artes cênic as, para além do racionalismo instrumental, signos verbais e matematização, o corpo não é apenas um receptáculo, algo possuído, inerte dos movimentos externos e internos, e que a consciência, responsável pela racionalização do mundo, é "uma operação que se realiza em toda parte do corpo. A consciência é corpórea" (SODRÉ, 2014, p. 12).

Há também uma contribuição do autor em que são consideradas outras demarcações para uma definição de corpo. Na Arkhé africana, ou seja, "na ritualização da origem e do destino" (SODRÉ, 2014, p. 15) o corpo é concebido como

(...) um microcosmo do espaço amplo (o cosmo, a região, a aldeia, a casa), igualmente feito de minerais, líquidos, vegetais e proteínas, para cuja formação e preservação acorrem elementos do presente cósmico e da ancestralidade. Para além da carne, o corpo e suas representações (portanto, a corporalidade) podem ser concebidos como um território onde se entrecruzam elementos fisicos e míticos e se erigem fronteiras e defesas. São as fronteiras, ou melhor, os limiares que separam o profano do sagrado. "Separar" vem do latim secernere, donde secretum (segredo), ou seja, o 
separado. Sacer (sagrado) é o território separado por limiares, não por barreiras como nas fronteiras. (Idem, 2014, p. 16, grifos nossos)

Nesse contexto podemos evocar um grande valor nas práticas religiosas da Umbanda, do Candomblé e outros cultos africanos e afro-brasileiros, na busca por umas práxis, uma filosofia que se desdobre apesar das racionalidades capitalistas de produção do sentido da vida. Até as definições para fronteiras, que normalmente significam "erguer barreiras", são centradas em uma outra perspectiva: "limiares", que sugerem uma atmosfera de mudança menos brusca e violenta ao qual as noções de fronteiras, barreiras territoriais nos fazem 'cosmoperceber'.

Para Sodré (2014), essas outras práticas reelaboram o espaço através do corpo. A música, como exemplo para o autor, tem servido como uma "tecnologia" de agregação humana. É através das festas, como o Carnaval, São João, ou como movimentos como o Brega Funk em Recife (Figura 7), que pessoas se unem através das expressões culturais, numa manifestação e elaboração essencialmente corpórea, reelaboram a produção espacial, ainda que em um lapso temporal curto/médio e reescrevem "as hierarquias territoriais, estimulando o poder expressivo do corpo até o ponto de produção de imagens próprias de liberação e auto realização" (p.1819).

Figura 7: Recife - Disputa de 'passinhos' realizada no Marco Zero, no bairro do Recife: Grupos disputam lugares e territórios através da dança de um dos ritmos musicais mais populares de Pernambuco.

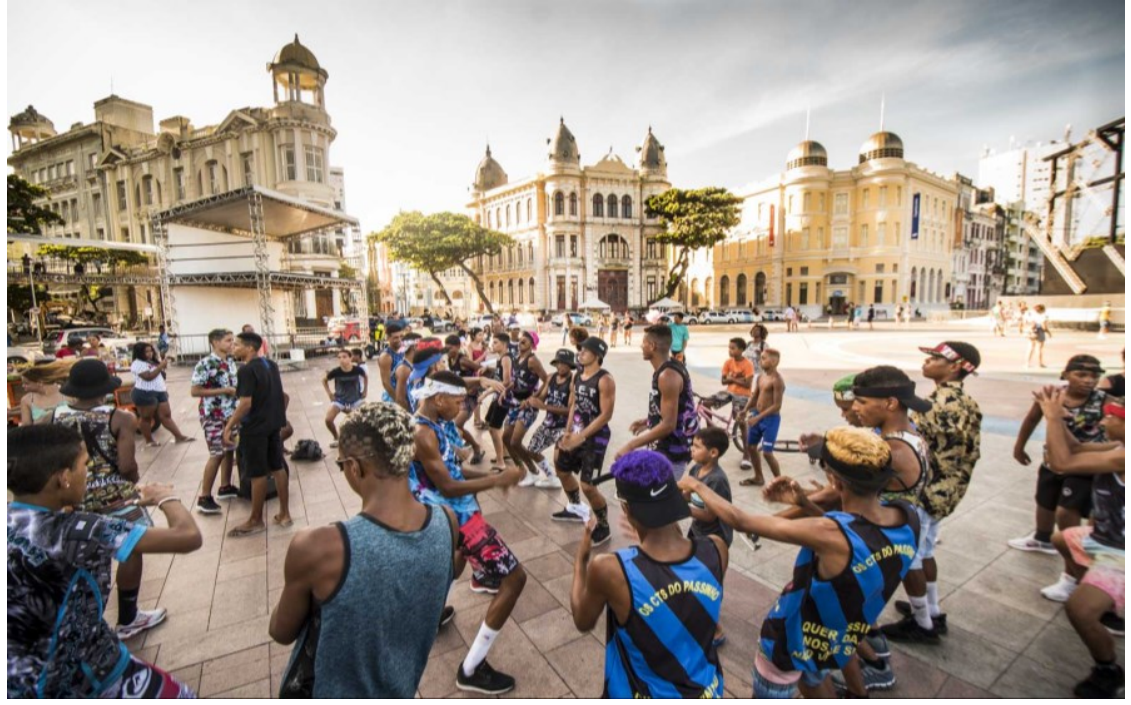

Fonte: Inês Campelo em reportagem do Marco Zero Conteúdo ${ }^{11}$

\section{A GEOGRAFIA TAMBÉM PRODUZ DEFINIÇÕES PARA “CORPO”}

\footnotetext{
${ }^{11}$ Disponível em: https://marcozero.org/racismo-policial-reprime-encontros-de-passinho-e-ja-fez-aprimeira-vitima/. Último Acesso em: 02/07/2021
} 
Em uma das suas mais famosas definições, a de território usado, Milton Santos (1999) nos presenteia com algo que nos parece ter sido despercebido na geografia até então. No trecho em que define 'território usado', Milton se refere ao corpo, sem propriamente usar o termo:

O Território é o lugar em que desembocam todas as ações, todas as paixões, todos os poderes, todas as forças, todas as fraquezas, isto é, onde a história do homem plenamente se realiza a partir das manifestações da sua existência. (...)O território usado é o chão mais a identidade. A identidade é o sentimento de pertencer àquilo que nos pertence. (SANTOS, 1999, p. 3-4)

Quando Santos fornece essa perspectiva para a definição de território, podemos extrapolá-la de algumas formas: 1) Há nessa definição forças que só podem ser compreendidas através de ações 'humanas', ou seja, a apropriação do espaço através das “ações”, "paixões”, "poderes" etc. só podem ser concebidas se tivermos corpos se relacionando em diversos níveis com o ‘espaço'. Se parte do que compreendemos como ‘território' está fundada numa operação humana: "o sentimento de pertencimento", ou a identidade, então precisamos fundamentalmente nos preocupar com o que imbrica-se nas realizações perceptivas 'humanas' que produzem o 'sentipensar' de pertencimento, levando em conta que essa operação só pode ser compreendida ser for corporificada, e o corpo, como tentamos elaborar aqui, pode ser explorado ontoepistemologicamente através de diversas perspectivas.

A geografia humanista, a exemplo de Tuan (2012), vem desde meados do século XX ressaltando a importância de modos de percepção na construção de uma geografia. Como exemplo, Tuan relata a construção de mapas mentais diferentes, de um mesmo lugar, em sociedades com papeis de gênero fortemente diferenciadas. Ou quando se constrói um sentimento específico, a “Topofilia”, pelo lugar onde se vive, se habita, explorando abertamente um campo corporificado para entender-se um processo geográfico.

Aliás, a noção de lugar, por exemplo, grande catalizadora do humanismo na geografia, leva em consideração diversos aspectos corporais para compreensão desta categoria, como o sentir, o perceber através dos sentidos, viver através de processos ontológicos e epistemológicos o lócus onde se habita. Então, não é exatamente uma novidade para a geografia compreender a forte ligação que se tem nas concepções do espaço, que levam em consideração a corporificação, o corpo, a corporeidade como centralidade na elaboração das suas categorias de análise.

As escolhas metodológicas que tomamos até então na ciência geográfica, tornaram invisíveis os caminhos de produzir uma geografia corporificada, onde o corpo-corporeidade 
fossem junto às categorias básicas de análise: "território, lugar, paisagem, espaço, região etc", consideradas relevantes para produção do conhecimento. Isso se deve, não só, as preocupações de outros tipos de análise que consideravam às perspectivas críticas, marxistas, pósestruturalistas como fornecedoras da racionalidade na leitura dos problemas de pesquisa, mas também percebemos uma gama de processos na estrutura epistemológica e ontológica da modernidade em inviabilizar a importância de abordagens que desmantelassem seus alicerces, como é também o caso de gênero, sexualidades e raça como estruturantes das práxis científicas.

\section{PROVOCAÇÕES FINAIS}

Há diversos caminhos possíveis para flexionar a polissemia do conceito de corpo para a geografia, incluindo aquelas que tratam-no de forma indissolúvel ao espaço, criando novas possibilidades, "caminhos imaginativos de espaço" (SILVA; ORNAT; JUNIOR, 2019, p. 64). Esses caminhos imaginativos, como bem lembra os autores citados, são conjugados a partir da trajetória das práxis 'ontoepistemológica' que cada corpo elabora em vida.

Embora a abertura de nossa elaboração, não esqueçamos que a produção do espaço é também fruto das coligações de forças sociais, da própria cultura. Esse processo de produção espacial, já apontado por Lefebvre (1991), nos faz pensar o quanto as relações de produção e as relações sociais são sempre carregadas de representações, que lhe servem de vitrine. Essas representações, sempre simbólicas, servem como meio de coerção, coexistência e coesão social, para que o aparato em voga funcione, está intrinsecamente ligada a produção dos saberes/ciências/conhecimentos.

Assim, para Lefebvre o espaço se produz nas práticas, interações, conflitos e vivências do envolvimento entre seus atores e elementos. Essas ações se correlacionam em um fluxo constante, mutável, em maior ou menores velocidades, que estão em uma 'mixórdia' de assimetrias de poder. Mas essa aparente mistura confusa, consegue ser em partes sistematizadas, de forma analítica, quando se criam categorias, lentes de análise da realidade social, das quais, o machismo, a lgbtfobia, o neoliberalismo, os corpos etc., fazem parte da produção do espacial e são produzidos por 'ele'.

Como, ainda somos extremamente influenciados pela racionalidade colonial nos nossos saberes, no nosso ser/estar (GRADA, 2020; LUGONES, 2008; MIRANDA, 2020; QUIJANO, 
2005), e adentramos profundamente em uma fase neoliberal do capitalismo globalizado (SANTOS, 2001), é necessário que provoquemos a produção científica em busca de significados outros para nossas crises, para os esgotamentos das formas já conhecidas de fazer política e governar (SODRÉ, 2014; MORAES e PARRA, 2020).

Entender as relações ontológicas entre espaço e corpo, é abrir caminho para novas epistemologias que valorizam o que temos tão nosso e nos conecta uns com os outros: nossas capacidades perceptivas, sensoriais, afetivas na relação com o mundo que criamos e que nos concebe. Assim podemos capinar caminhos da crítica feminista, ao compreender ventre como o primeiro território de vida (MELO, 2013), compreender a mãe terra, Pachamama, como corpo/corporalidade, "pluriverso cultural-natural ou conjunto de mundos - e, consequentemente, de territorialidades - aos quais estamos inexoravelmente atrelados" (HAESBAERT, 2020, p. 76), ou entende-lo como espaço íntimo, primeiro território de defesa, de embate de poderes e constituições (DE CAMPOS; SILVA; SILVA, 2020), ou simplesmente admitir que nossas categorias já, de certa forma, conjugam o corpo e suas operações para serem concebidas, nos resta então valorizar esses aspectos constitutivos.

É necessário que empreendamos recursos e energias para compreender as possibilidades, metodologias, epistemologias, ontologias por detrás de uma pesquisa geográfica que tenha o corpo como centralidade discursiva. Este artigo trouxe parte dessa busca, que se encontra ramificada nos mais variados campos do saber e é elaborada por muitos outros autores, sujeitos e coletividades que não constam aqui, como a valiosa contribuição de Sennet (2014), onde se perscruta como a produção de uma segregação sócio espacial produz formas de passividades e sofrimentos nas (os) sujeitas (os) que o vivem (NASCIMENTO, 2016).

Há muito potencial a ser explorado na ciência geográfica caso sejamos corajosos de rever nossas epistemologias coloniais e abrir as portas para conceber, profundamente, novas formas de estar e ser no mundo, ouvindo, principalmente, sujeitos e coletividades marginalizados pelo sistema de produção-mundo dominante, e assim explorar novos "topos", ou seja, descrever novos lugares, novos caminhos onde a geografia possa percorrer e criar suas "grafias" sob lócus do conhecimento pouco explorados por nossa ciência, e fornecer ao debate público uma construção de um outro sistema-mundo onde se proliferem as formas de cultuar a vida diferentes daquelas que desapropriam, matam, destroem, usurpam. É urgente que comecemos a proliferar essas ideias, principalmente dada as características únicas de nossa 
contemporaneidade fascista, autoritária, machista, masculina, heteroconforme, LGBT+ fóbica. Como já tinha nos avisado Pitty, há anos atrás:

\author{
Nós não temos todo tempo do mundo \\ E esse mundo já faz muito tempo \\ O futuro é o presente \\ E o presente já passou (Trecho da canção "Semana que vem", 2003)
}

\title{
REFERÊNCIAS
}

ACOSTA, S. Cuerpo/territorio. ÍCONOS, Revista de Ciências Sociales, No 61, Equador, ISSN: 1390-1249. DOI: http://dx.doi.org/10.17141/iconos.61.2018.3316. 2018.

ANDRADE, D. P. O que é o neoliberalismo? A renovação do debate nas ciências sociais. Sociedade e Estado, v. 34, n. 1, p. 211-239, 2019.

BARAD, K. "Performatividade pós-humanista: para entender como a matéria chega à matéria". Vazantes, Fortaleza, v. 1, n.1, pp. 8-34, 2017.

BUTLER, J Gender trouble: Feminism and the subversion of identity. routledge, 1999.

Bodies in Alliance and the Politics of the Street. Transversal. European Institute for Progressive Cultural Politics. 2011.

CASTRO-GÓMEZ, S. Ciências sociais, violência epistêmica e o problema da "invenção do outro". In: LANDER, E. A colonialidade do saber: eurocentrismo e ciências sociais latinoamericanas. Buenos Aires: CLACSO, 2005.

DE CAMPOS, M. P; SILVA, J. M; SILVA, E. A. 'Teu corpo é o espaço mais teu possível': Construindo a análise do corpo como espaço geográfico. Revista da ANPEGE, v. 16, n. 31, p. 101-114, 2020.

DE LIMA, E. L. Do corpo ao espaço: contribuições da obra de Maurice Merleau-Ponty a Análise Geográfica. GEOgraphia, v. 9, n. 18, 2007.

DUNKER, C. Reinvenção da intimidade: políticas do sofrimento cotidiano. São Paulo: Ubu Editora, 2017.

HAESBAERT, R. Do corpo-território ao território-corpo (da terra): contribuições decoloniais. GEOgraphia, v. 22, n. 48, 2020.

LE BRETON, D. Antropologia do corpo e da modernidade. Petrópolis: Editora Vozes, 2012.

LEFEBVRE, H. The Production of Space. Oxford: Blackwell, 1991.

FOUCAULT, M. Naissance de la biopolitique. Paris: Seuil; Gallimard, 2004.

GONÇALVES, J. R. Metodologia Científica e Redação Acadêmica. 8. ed. Brasília: JRG, 2019a. Como escrever um Artigo de Revisão de Literatura. Revista JRG de Estudos Acadêmicos, v. 2, n. 5, p. 29-55, 2019 b.

LUGONES, M. Colonialidad y género. Tabula rasa, n. 09, p. 73-101, 2008.

KILOMBA, G. Memórias da plantação: episódios de racismo cotidiano. Editora Cobogó, 2020 . 
MELO, C. P. L. A (des)colonialidade do parto: reflexões sobre o movimento de humanização da parturição e do nascimento. In: XXIX Congreso de la Asociación Latinoamericana de Sociología 2013, 2013, Santiago do Chile. Acta Científica XXIX Congreso de la Asociación Latinoamericana de Sociología 2013, 2013.

MERLEAU-PONTY. M. Fenomenologia da Percepção. São Paulo: Martins Fontes. 1999.

MIRANDA, E. O. Corpo-território \& educação decolonial: proposições afro-brasileiras na invenção da docência. Salvador: EDUFBA, 2020.

MORAES, A; PARRA, H ZM. Laboratórios do comum: experimentações políticas de uma ciência implicada. Revista do Centro de Pesquisa e Formação, p. 113-139, 2020

NASCIMENTO, S. A cidade no corpo. Diálogos entre corpografia e etnografia. Ponto Urbe. Revista do núcleo de antropologia urbana da USP, n. 19, 2016.

PATZDORF, D. Artista-educa-dor: A somatopolítica neoliberal e a crise da sensibilidade do corpo ocidental. Urdimento-Revista de Estudos em Artes Cênicas, v. 1, n. 40, p. 1-28, 2021.

PRECIADO, P. B. Trad. Maria Paula Gurgel Ribeiro. Texto Junkie: sexo, drogas ebiopolítica na era farmacopornográfica. São Paulo: n-1 edições, 2018.

QUIJANO, A. A colonialidade de poder, eurocentrismo e América Latina. In: LANDER, E. A colonialidade do saber: eurocentrismo e ciências sociais latino-a-mericanas. Buenos Aires: CLACSO, 2005.

SAFATLE, V; SILVA JR, N; DUNKER, C. Neoliberalismo como gestão do sofrimento psíquico. Belo Horizonte: Autêntica Editora, 2021.

SANTOS, M. A natureza do espaço: técnica e tempo, razão e emoção. Edusp, 1996.

Por uma outra globalização: do pensamento único à consciência universal. $6^{\mathrm{a}}$ Edição. Rio de Janeiro: Record, .2001

O dinheiro e o território. GEOgraphia, v. 1, n. 1, p. 7-13, 1999.

SILVA, J. M; ORNAT, M. J; JUNIOR, Alides Baptista Chimin. Geografias malditas: corpos, sexualidades e espaços. Todapalavra editora, 2013.

. Corpo como espaço: um desafio à imaginação geográfica. Pluralidades dos Sujeitos: representações e ações no território. Porto Alegre-Brasil. Editorial: Compasso Lugar e Cultura, p. 56-75, 2016.

SILVA, J. M; ORNAT, M. J; JUNIOR, A. B. C. O legado de Henri Lefebvre para a constituição de uma geografia corporificada. Caderno Prudentino de Geografia, v. 3, n. 41, p. 63-77, 2019.

SODRÉ, M. Cultura, corpo e afeto. Dança: Revista do Programa de Pós-Graduação em Dança, v. 3, n. 1, 2014.

TUAN, Yi-Fu. Topofilia: um estudo da percepção, atitudes e valores do meio ambiente. SciELO-EDUEL, 2012.

WOODYER, T. The body as research tool: embodied practice and children's geographies. Children's Geographies, v. 6, n. 4, p. 349-362, 2008 